\title{
Of great art and untalented artists: Effort information and the flexible construction of judgmental heuristics
}

\author{
Hyejeung Cho ${ }^{\mathrm{a}, *}$, Norbert Schwarz ${ }^{\mathrm{b}, \mathrm{c}, \mathrm{d}}$ \\ ${ }^{a}$ University of Texas at San Antonio, Department of Marketing, One UTSA Circle, San Antonio, TX 78249-0638, USA \\ ${ }^{\mathrm{b}}$ University of Michigan, USA \\ ${ }^{\mathrm{c}}$ Ross School of Business, USA \\ dinstitute for Social Research, University of Michigan, Ann Arbor, MI 48106-1248, USA
}

Available online 25 June 2008

\begin{abstract}
Past research (Kruger, Wirtz, Van Boven, \& Altermatt, 2004) proposed that people use the effort of the producer as a heuristic for the quality of the product. In contrast, two experiments show that consumers' inferences from effort information are highly malleable. Participants were either explicitly exposed to one of two applicable naive theories ("good-art-takes-effort" vs. "good-art-takes-talent") or the order of judgment was reversed (quality judgment first vs. talent judgment first) to activate different naive theories more subtly. In both cases, participants only inferred high quality from high effort when an "effort" theory was rendered accessible, but not when a "talent" theory was rendered accessible. We conclude that judgment tasks prime naive theories that can serve as inference rules, illustrating that heuristics can be constructed on the spot. (C) 2008 Society for Consumer Psychology. Published by Elsevier Inc. All rights reserved.
\end{abstract}

Suppose that you are attending a local art fair looking for a painting for your home. You see a nice piece but can't tell whether the price tag of $\$ 1000$ is reasonable. Noticing your interest, the artist approaches you and you learn that it took him more than a year to complete the painting. Research by Kruger, Wirtz, Van Boven, and Altermatt (2004) suggests that this effort information may make you more inclined to purchase the painting. Specifically, they observed that perceivers evaluated a variety of objects more favorably, and were willing to pay a higher price, the more effort the producer had invested. Presumably, people assume that good work takes time and effort, and hence infer high quality from high effort information. But suppose a friend listened to your conversation and whispers into your ear, "It took him more than a year? How talented do you think he is?" If your reaction is like ours, you may start wondering about the quality of the picture.

In general terms, we propose that we cannot predict perceivers' inferences when we merely know which input information they draw on, in this case, information about the effort that went into the painting. To move from this information to a judgment of quality, perceivers need to draw on background

\footnotetext{
* Corresponding author.

E-mail address: hyejeung.cho@utsa.edu (H. Cho).
}

knowledge that links the input to the target judgment. We refer to this knowledge as perceivers' naive theories about the respective content domain. In the present case, one naive theory holds that high quality products require careful work, which entails considerable effort. Application of this theory results in a positive influence of perceived high effort on quality judgments, as captured by the effort heuristic of Kruger et al. (2004). However, another plausible naive theory holds that skilled and talented producers need to invest less effort than unskilled and untalented producers for the same quality output. When perceivers apply this theory as an inference rule, high effort would raise some doubts about the producer's talent, which renders the effort information nondiagnostic for judgments of quality. In this case, the operation of the effort heuristic (Kruger et al., 2004) should no longer be observed and perceivers may even infer lower quality from higher effort. ${ }^{1}$ Experiment 1 provides a direct test of this hypothesis by explicitly manipulating the accessibility of the respective naive theory.

\footnotetext{
${ }^{1}$ Kruger et al. (2004) acknowledged the possibility that high effort information may occasionally lead to a low quality judgment by suggesting that "the type of effort involved may be a key moderator ..." (p.97). We agree More important, we propose that identical effort information may lead to different judgments depending on which naive theory is applied as an inference rule.
} 
More important from a theoretical perspective, we propose that the judgment task itself influences which of several applicable naive theories perceivers bring to mind (Schwarz, 2004a,b). Perceivers who are first asked to evaluate the quality of a painting for which they have received effort information are likely to draw on a naive theory that directly links effort and quality; assuming that good work takes time, they will infer high quality from high effort. In Kruger et al. (2004), participants assessed the quality of poems (Experiment 1), paintings (Experiment 2), and armors (Experiment 3) after receiving either high or low effort information. In their experiments, the higher perceived effort consistently led to higher perceived quality, presumably because the quality judgment task itself brought the 'good-work-takes-time' theory to mind.

However, perceivers who are first asked to judge the artist's talent (before judging the quality) should be likely to draw on a theory that directly links effort and talent; assuming that talented producers are fast, they may hesitate later on to infer high quality from high effort. Experiment 2 tests this judgment order prediction. Support for this prediction would suggest that people construct applicable heuristic inference rules on the spot, rendering the application of heuristics highly malleable. We return to this issue in the discussion.

In sum, we propose (i) that the same input information results in different inferences, depending on the naive theory that serves as an inference rule; (ii) that applicable naive theories are recruited by the judgment task; and (iii) that application of one theory can change the implications of the input information for inferences that require the application of a different theory, resulting in pronounced judgment order effects.

\section{Experiment 1: Different naive theories explicitly primed}

People hold a variety of beliefs about the association of attributes that can serve as inference rules in making judgments of personality (e.g., Schneider, Hastorf, \& Ellsworth, 1979) or product quality (e.g., Kardes, Posavac, \& Conley, 2004). These beliefs often include causal assumptions (Nisbett \& Ross, 1980), like the belief that high effort or high talent fosters high quality of the produced output. Consistent with the terminological tradition in person perception research, we refer to such beliefs as naive theories. A pretest with 22 university students indicated that the naive theories of interest to the present experiments are widely shared by our participant population. Specifically, $86.4 \%$ of the pretest participants agreed with the statement, "Good work takes time," and $100 \%$ of respondents agreed with the statement, "High quality products usually require more careful work than low quality products." More importantly, $90.9 \%$ also agreed that "Talented producers need to invest less time than untalented producers to achieve the same quality output," and $86.4 \%$ of respondents agreed that "Unskilled producers need to invest more time and effort in the creation process than skilled producers for the same quality output." The high agreement with these statements indicates that people hold multiple naive theories that may give rise to different inferences about the relationship between production effort, product quality, and the producer's talent.
To render these different beliefs highly accessible, participants in Experiment 1 read a short paragraph that emphasized either the role of effort or the role of talent in the production of great art. Subsequently, they evaluated the quality of a picture as part of an allegedly separate study. We predicted that the previously observed high effort-high quality relationship (Kruger et al., 2004) would replicate when a "good-art-takeseffort" theory is rendered accessible, but not when a "good-arttakes-talent" theory is rendered accessible.

\section{Method}

\section{Participants and design}

172 undergraduate students were randomly assigned to the conditions of a 2 (effort information: high vs. low effort) $\times 2$ (presented theory: effort theory vs. talent theory) factorial design with a non-factorial control group.

\section{Materials and procedure}

Participants were asked to participate in multiple unrelated studies that were grouped together for efficiency. For participants assigned to the experimental conditions, the alleged first study served the manipulation of theory accessibility and followed procedures used by Chiu, Dweck, Tong, and Fu (1997) and McConnell (2001). Participants were told that the study examined the influence of time delay on memory and were asked to read a short article, for which they would later receive a comprehension and memory test. The article reported on a presentation by an art historian who emphasized either the role of effort or the role of talent in the production of great art. The key paragraphs are shown in the Appendix.

Next, participants completed a short filler task, presented as a second study, asking them to compare and evaluate four different electronic products, before they turned to an alleged third study, entitled 'Auction Study'. This third study was introduced as a study of consumer judgment and participants were asked to evaluate a contemporary painting, allegedly chosen at random from a larger pool of paintings at an art auction. Along with a picture of the painting, they received basic information about the art work, including the painting's title (May's End), the artist's name (William Morehouse), the year (2004), the media used (Oil on Canvas), and the original size of the painting $(36 \times 32$ in). Additional information, allegedly provided by the painter, informed them how long the painter had worked on the painting. Some participants were told that it had taken the artist more than 1 year to finish the art work (high effort condition), whereas others learned that it had taken him two to three days (low effort condition). Participants' task was to estimate for how much money the painting would sell at an auction; they provided their estimate along a 10-point scale $(1=$ less than $\$ 100 ; 10=$ more than $\$ 3500)$.

Following the estimate, the alleged second part of the initial comprehension and memory study was introduced to collect various manipulation checks. Specifically, participants summarized the main message they had read in their own words, thus providing a measure of how carefully they had read the article that served as the manipulation of theory accessibility. In 
addition, they rated the article read in terms of its comprehension difficulty, credibility, and persuasiveness (on scales of 1 to 7 , with 7 indicating high difficulty, credibility, and persuasiveness, respectively).

Participants assigned to the non-factorial control condition were not exposed to the theory manipulation (alleged first study) and estimated the auction price of the painting without learning about the painter's effort. Their estimates provide a baseline based on exposure to the painting, its title, and the name of the artist.

As a last step, participants were probed for suspicion and wrote down what they thought the research hypotheses were. At the end, all participants received debriefing information including the true information about the painting ("May's End" by William Morehouse (1929-1993), Oil on Canvas, $1960,36 \times 32 \mathrm{in}$ ), purpose of the study, and experimental manipulations.

Results

\section{Manipulation checks}

The memory measure indicated that 16 of the 172 participants did not recall the main point of the article they had read. 10 participants reported suspicion and guessed that the "comprehension and memory" study and the "auction" study were related. Finally, five reported that they were already familiar with the painting. All of these participants were excluded from further analyses, leaving 141 participants in the study. ${ }^{2}$

The two articles that served as theory manipulations did not differ in terms of their perceived comprehensibility, credibility and persuasiveness, all $t$ 's $<1.5, n s$.

\section{Value of the painting}

We first conducted a 2 (effort) $\times 2$ (theory) analysis of variance (ANOVA) on the factorial portion of the data. As shown in Fig. 1, participants who were exposed to the effort theory predicted that the painting would sell at a higher price when it took the artist more than a year to produce it $(M=6.37 ; S D=2.76)$ rather than only $2-3$ days $(M=3.82$; $S D=1.61) ; F(1,113)=17.47, p<.001$, for the simple main effect. In contrast, the artist's effort did not exert a significant influence when participants were exposed to the talent theory $(M$ 's $=4.78$ and 5.27; $S D$ 's $=2.39$ and 2.60, for low and high effort, respectively); $F<1$, for the simple main effect. This pattern of results is reflected in the predicted interaction of effort and presented theory, $F(1,113)=12.13, p<.005$.

A non-factorial control group estimated the picture's auction price $(M=3.96 ; S D=1.99)$ without being exposed to an applicable naive theory or information about the painter's effort. Comparisons with this control group indicate that only the two experimental conditions in which the primed theory matched the effort information differ from baseline. Specifically, participants primed with the effort theory provided a price

\footnotetext{
${ }^{2}$ Including all participants in the analyses did not change the pattern of results.
}

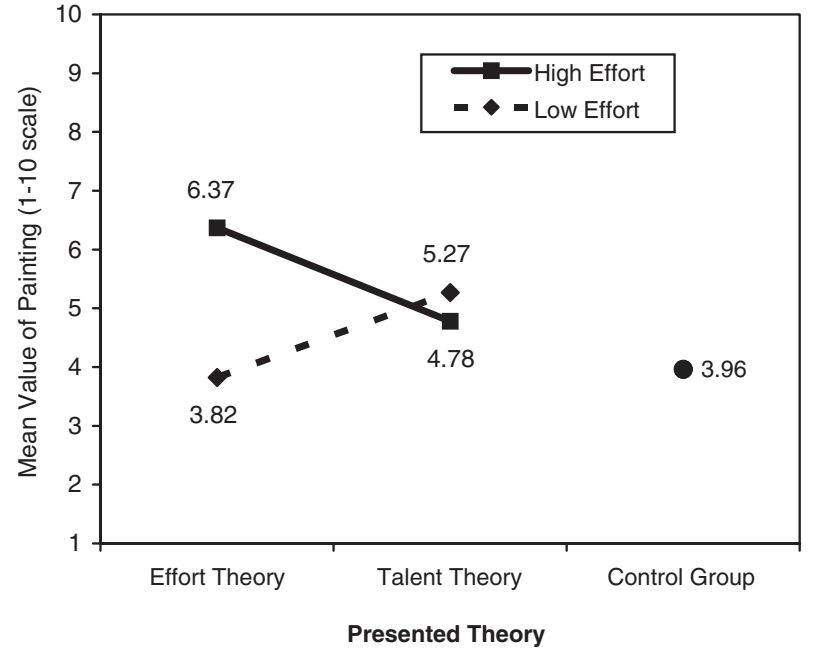

Fig. 1. Mean of the 'perceived monetary value of the painting' as a function of 'presented theory' and 'effort information' (Experiment 1).

estimate above baseline when the painter's effort was high $(F(1,136)=14.03, p<.001$, for the contrast $)$, but not when it was low $(F<1$, for the contrast). Conversely, participants primed with the talent theory provided a price estimate above baseline when the painter's effort was low $(F(1,136)=4.33, p<.05$, for the contrast), but not when it was high $(F<2, n s$, for the contrast).

\section{Discussion}

In sum, participants' inferences from effort information depended on which of two applicable naive theories was rendered accessible by an earlier manipulation. After reading that producing good art requires a lot of effort, participants predicted that the same picture would sell at a higher price when they learned that the artist had worked on it for more than a year rather than for 2-3 days. Moreover, their price estimates only exceeded the estimates of a control group that had not been exposed to a relevant theory or to effort information when the artist's effort was high, thus satisfying the key quality predictor specified by the primed theory. Conversely, after reading that producing good art requires a lot of talent, participants' price estimates only exceeded the baseline condition when the artist's effort was low. Given participants' assumption that talented producers need to invest less effort (as indicated by our pretest data), low effort presumably highlighted the artist's talent, whereas high effort called it into question. Accordingly, these participants also evaluated the picture nonsignificantly more favorably under low than high effort conditions.

In combination, these results confirm the reasonably obvious prediction that the application of different inference rules to the same input data results in different judgments. One plausible, and theoretically not very exciting, conclusion is that Kruger et al. (2004) observed a robust influence of effort on quality judgments because the relevant naive theory is chronically accessible. Replacing this theory with an alternative one requires a heavy-handed manipulation of the type used here. 
Alternatively, however, the judgment process may be more malleable than standard theorizing about the application of heuristic inference rules assumes. We now turn to this possibility, which motivated the present research.

\section{Experiment 2: Naive theories activated by judgment tasks}

Whereas Experiment 1 explicitly exposed participants to one of two applicable naive theories, Experiment 2 tests whether the judgment task itself is sufficient to bring the respective theory to mind. When asked to judge the quality of a painting, participants need to draw on a plausible inference rule that allows them to form a quality judgment on the basis of the available information. If they have effort information at hand, they may use a good-work-takes-time theory, resulting in an inference of high quality from high effort, as observed in Experiment 1 and initially reported by Kruger et al. (2004). Once they inferred high quality, they may also conclude that the artist has high talent - after all, he produced a high quality piece of art. But when first asked how talented the artist is, the judgment task may bring the alternative talented-people-arefast theory to mind, thus calling the effort-quality association into question. In this case, the artist's effort may either be discounted as uninformative or may give rise to the opposite conclusions.

To test these possibilities, we conducted a modified replication of Experiment 1, asking participants to judge the painting's quality and likely auction price as well as the painter's talent. We predicted that high effort would result in high quality, value, and talent judgments when quality is evaluated first, but not otherwise.

\section{Method}

\section{Participants and design}

One hundred undergraduate students were randomly assigned to the conditions of a 2 (effort information: high vs. low effort) $\times 2$ (judgment task: quality vs. talent judgment first) factorial design. Three participants guessed the purpose of the study, one was familiar with the painting and the painter used in the experiment, and the open-ended price estimates of three participants were extreme outliers; these seven participants were excluded from data analyses, reducing the total $\mathrm{N}$ to $93 .^{3}$

\section{Materials and procedure}

Participants received a questionnaire entitled "Artistic Judgment Study" which described the experiment as a study of artistic impressions. Participants were shown the same painting used in Experiment 1 (May's End) and also received similar basic information on the painting and the artist's creation process. In the high effort condition, participants learned that it had taken the artist more than 1 year to finish the art work and that he had drawn more than 15 sketches before completing the painting; in the low effort condition, they

\footnotetext{
${ }^{3}$ Including these participants did not change the pattern of results.
}

learned that it had taken him 2-3 days to finish the painting and that he had drawn no idea sketch.

Participants assigned to the quality-first condition first rated the overall quality of the painting $(1=$ not so good; $11=$ very good), estimated the amount of money they thought it would sell for at an art auction (as an open-ended response in USD), and finally indicated how talented they thought the painter was $(1=$ not so talented; $11=$ very talented $)$. Participants assigned to the talent-first condition made the same judgments in reverse order (i.e., talent, auction price, and quality). Finally, all participants indicated whether they had seen the painting or the artist's other paintings before, were probed for suspicion, and fully debriefed.

\section{Results}

\section{Quality of the painting}

Our theoretical rationale predicts that high production effort results in inferences of high product quality only when perceivers do not consider the producer's talent first. As shown in Table 1, the data support this prediction. In the qualityfirst condition, participants evaluated the same painting more favorably when they assumed that the artist invested a high rather than a low degree of effort; $F(1,89)=11.95, p<.01$, for the simple main effect. This replicates the results of Kruger et al. (2004). However, when participants first thought about the talent of the artist, the influence of effort on judgments of quality was eliminated; $F<1$ for the simple main effect. This pattern of results is reflected in the predicted interaction of effort and question order, $F(1,89)=9.84, p<.01$. No other effects were significant.

\section{Value of the painting}

Following their initial judgment (of either quality or talent), participants estimated for how much money the painting would sell at an art auction. Unlike Experiment 1, where ranges of US dollar values were pre-assigned to a ten-point scale, participants provided their price estimates as an open-ended response in USD. As shown in Table 1, their value estimates mirror the pattern of the quality judgments and are consistent with the value estimates obtained in Experiment 1. However, due to very high variance in the open-ended dollar responses (which ranged from $\$ 18$ to $\$ 15,000 ; \mathrm{SD}=\$ 2874)$, the interaction of effort and judgment order failed to reach significance, $F(1,89)=2.49, n s$.

Table 1

Means and standard deviations of 'perceived quality of the painting' and 'perceived talent of the artist,' and medians and standard deviations of 'perceived monetary value of the painting' (Experiment 2)

\begin{tabular}{|c|c|c|c|c|}
\hline & \multicolumn{2}{|c|}{ Quality-first condition } & \multicolumn{2}{|c|}{ Talent-first condition } \\
\hline & High effort & Low effort & High effort & Low effort \\
\hline Perceived quality & $6.85(2.03)$ & $5.00(1.50)$ & $5.29(1.88)$ & $5.75(1.66)$ \\
\hline $\begin{array}{l}\text { Median perceived } \\
\text { value }\end{array}$ & $\$ 1250(\$ 2788)$ & $\$ 500(\$ 3341)$ & $\$ 425(\$ 2233)$ & $\$ 800(\$ 3077)$ \\
\hline Perceived talent & $7.30(1.84)$ & $5.58(1.82)$ & $5.21(1.77)$ & $5.80(1.85)$ \\
\hline
\end{tabular}

Note. Standard deviations are in parentheses. 


\section{Talent of the artist}

Finally, participants' talent judgments also revealed the predicted interaction of effort and judgment order, $F(1,89)=$ $9.31, p<.01$. Not surprisingly, participants who had just provided a positive evaluation of the painting also inferred that the painter is talented, resulting in a positive influence of effort on their talent judgments in the quality-first condition, $F(1,89)=9.73, p<.01$, for the simple main effect. In contrast, when participants made the talent judgment first, they tended to perceive the artist as being somewhat less talented in the high than in the low effort condition, although this pattern did not reach significance $(F<1.5$, for the simple main effect).

This pattern also resulted in a significant main effect of judgment order, $F(1,89)=6.14, p<.05$, that is qualified by the above interaction. Overall, participants judged the artist to be more talented when the quality rather than talent judgment came first $(M ` s=6.36$ and 5.51 , respectively). No other effects were significant.

\section{Discussion}

In sum, participants' inferences from effort information were strongly influenced by judgment order. Most importantly, participants inferred high quality from high effort when the quality judgment was assessed first, but not when it followed a talent judgment. Presumably, the talent judgment brought an alternative naive theory to mind ("talented producers are fast") that undermined the informational value of the effort information. This interpretation is supported by the results of Experiment 1, in which a more direct manipulation of applicable naive theories had parallel effects on price estimates as an indicator of quality.

\section{General discussion}

As the German philosopher Gottfried Wilhelm Leibniz (1646-1716) noted, any given piece of data is compatible with numerous different theories (Magee, 1985). This applies to real life as to science, and people's inferences from a given piece of information depend on the naive theory that they apply as an inference rule. Investigating the role of effort information in quality judgments, Kruger and colleagues (2004) identified one such theory. People assume that good work takes time and effort, and hence infer quality from effort. However, this effort heuristic is not the only naive theory applicable to effort information. People also assume, for example, that talented producers are fast and need to invest less effort than untalented producers to arrive at a product of comparable quality. As our pretest indicated, both theories were endorsed by an overwhelming majority of participants, their somewhat conflicting implications notwithstanding. When people apply these naive theories to the same effort information, they should arrive at different inferences. Not surprisingly, they do.

In Experiment 1, we explicitly exposed participants to material that suggested either that producing good art takes effort or that it takes talent. As predicted, effort information only exerted a significant influence on participants' assessments of the painting when an applicable effort theory was primed. Having set the stage with a somewhat heavy-handed manipulation in Experiment 1, we tested in Experiment 2 whether the judgment task itself is sufficient to recruit an applicable theory. As expected, effort information exerted a significant influence on participants' evaluation of the painting when the first judgment pertained to the painting's quality, replicating the results of Kruger et al. (2004). However, no significant influence of effort information was observed when the first judgment pertained to the artist's talent, thus bringing a competing theory to mind.

In fact, effort information tended to have a reverse impact on participants' assessments of the painting when a talent theory was rendered accessible. Most notably, talent-primed participants who learned that the artist spent only $2-3$ days on the painting estimated that it would sell at a higher price than participants assigned to a no-prime control group that received no effort information (Experiment 1); yet learning that it took the artist more than a year to complete the painting did not lower its perceived value relative to control conditions. This asymmetric impact is consistent with the implications of a talent theory: Being able to produce a nice painting in a short time implies high talent, but taking one's time does not necessarily imply low talent. In addition, the pattern of participants' judgments consistently showed a more favorable evaluation of the painting under low effort conditions whenever a talent theory was rendered accessible (Experiments 1 and 2), although these effects did not reach significance. The overall weaker impact of effort information under talent than under effort theory conditions is consistent with the differential diagnostic value of effort information in the context of these naive theories.

\section{Implications}

These findings have theoretical, methodological, and applied implications. On the theoretical side, they highlight that merely knowing which input information people draw on does not allow us to predict their judgments. Instead, we need to understand the inference rules that they are likely to apply. These inference rules can be thought of as naive theories that link the input variable to the to-be-judged attribute of the target. As demonstrated by the order effects observed in Experiment 2, applicable theories are recruited by the respective judgment task (Schwarz, 2004a). More important, application of a given theory entails a causal attribution, e.g., "He was so fast because it is low quality work" vs. "He was so fast because he is really talented." These attributions will usually render the initial input information uninformative for judgments that require the application of a different naive theory - once low quality is inferred, high talent no longer follows and vice versa. Occasionally, however, the attribution underlying the initial judgment will also have implications for subsequent judgments, resulting in carry-over effects. For example, the conclusion that the product is of high quality implies that the producer is talented because untalented people rarely produce high quality work. As a result, order effects can be 
asymmetrical. Similar results have been obtained in other domains, including the inferences that people draw from their own feelings and meta-cognitive experiences (e.g., Xu \& Schwarz, 2005; see Pham, 2004; Schwarz, 2004a; Schwarz \& Clore, 2007, for a discussion). Such findings highlight that applicable heuristics are often constructed on the spot to allow the person to get from "here" (the available data) to "there" (the requested judgment). Future research may fruitfully explore to which extent the recruitment of different inference rules is influenced by variables known to affect other aspects of mental construal, like processing motivation and style (e.g., Strack, Werth, \& Deutsch, 2006; Wyer, Hung, \& Jiang, in press), affective state at the time of judgment (e.g., Han, Lerner, \& Keltner, 2007; Schwarz \& Clore, 2007), psychological distance (Trope, Liberman, \& Wakslak, 2007), and environmental primes (Dijksterhuis, Smith, van Baaren, \& Wigboldus, 2005).

In addition, the observed malleability of participants' inference strategies highlights several methodological challenges for judgment research. First, the observation that judgment tasks recruit applicable naive theories as inference rules implies that there is no "neutral" condition that reliably captures what people would spontaneously think in a natural context. As soon as a question is posed as the dependent variable, it may bring theories to mind that the person may otherwise not think of. As the parallel effects of explicit priming (Experiment 1) and judgment order (Experiment 2) illustrate, the dependent variable itself serves as a prime, turning the act of measurement into an experimental treatment. Second, the observed malleability further implies that many judgment effects are probably less robust than the experimental literature suggests. As long as the tasks presented by the experimenter recruit the same naive theories, and do so in the same order, observed results are likely to replicate across different stimuli (e.g., Kruger et al., 2004). However, as seen in the present research, a mere change in judgment order can recruit a different inference rule, resulting in qualitatively different judgments. This may be at the heart of many failures to replicate prior results, which would have been robust had the same question order been observed. Unfortunately, this malleability also highlights the difficulties involved in generalizing from experimental results to natural contexts. Short of knowing which questions people ask themselves spontaneously it is difficult to predict which of many applicable naive theories they will draw on - and presenting the dependent variable may override whatever may have come to mind spontaneously.

Finally, on the applied side, our findings illustrate that informing consumers that it took a lot of effort to produce an object does not necessarily boost consumers' perceptions of high quality. Knowing that it took a tailor 6 months to finish your suit (rather than the common 4-6 weeks) does not necessarily guarantee that you will want to pay more for the garment - in fact, it may only raise doubts about his skill and talent. Future research may fruitfully explore which aspects of a consumption situation, and which goals, give rise to which naive theory in the wild.

\section{Appendix A}

The following paragraphs served as manipulations in Experiment 1.

Dr. Myles, in his concluding remarks, highlights the great artists' effort put in their artwork.

"When you stand in a museum, say the Prado or the Louvre, and contemplate the art before you, be it a sculpture or a painting, what impresses you first would be the artist's creativity or skill shown in the artwork. You might think that great artists are simply born with great talent, making it easy for them to create a masterful work of art. However, the fact is that the great artists were not just born to create. You will be surprised to know the enormous amount of time and effort that went into the creating of their artistic masterpieces. Confirming the truism that "Good work takes time," many historical records and studies provide evidence that the most important thing that all great artists had in common was their persistent effort and enduring hard work. They were always determined to overcome difficulties and setbacks in the long creation process. Without their effort and determination, most influential masterpieces would have never been born. Great art is not just the finished work but also the sweat and effort that made it possible."

Dr. Myles, in his concluding remarks, highlights the great artists' artistic instinct and talent.

"When you stand in a museum, say the Prado or the Louvre, and contemplate the art before you, be it a sculpture or a painting, what impresses you would be the creativity and the talent shown in the artwork. You may be even more surprised and impressed once you realize that many masterpieces were created in a short period of intense creativity. Confirming our naive theory of creativity and talent, many historical records and studies provide evidence that the great artists in the world's history were really born with the creativity and they were truly gifted in one way or another. Without their talent, they would have never been able to create such influential masterpieces only in a matter of days or sometimes even hours. The great art does seem to be born by the artist's inspiration. These artists knew how to let their artistic talent lead them throughout their creation process. Great art is not just the finished work but also the inspiration and the creative talent that made it possible."

\section{References}

Chiu, C., Dweck, C. S., Tong, J. Y., \& Fu, J. H. (1997). Implicit theories and conceptions of morality. Journal of Personality and Social Psychology, 73, 923-940.

Dijksterhuis, A., Smith, P. K., van Baaren, R. B., \& Wigboldus, D. H. J. (2005). The unconscious consumer: Effects of environment on consumer behavior. Journal of Consumer Psychology, 15, 193-202.

Han, S., Lerner, J. S., \& Keltner, D. (2007). Feelings and consumer decision making: The appraisal-tendency framework. Journal of Consumer Psychology, 17, 158-168.

Kardes, F. R., Posavac, S. S., \& Cronley, M. L. (2004). Consumer inference: A review of processes, bases, and judgment contexts. Journal of Consumer Psychology, 14, 230-256. 
Kruger, J., Wirtz, D., Van Boven, L., \& Altermatt, T. W. (2004). The effort heuristic. Journal of Experimental Social Psychology, 40, 91-98.

Magee, B. (1985). Philosophy and the real world: An introduction to Karl Popper. Open Court Publishing Company.

McConnell, A. R. (2001). Implicit theories: Consequences for social judgments of individuals. Journal of Experimental Social Psychology, 37, 215-227.

Nisbett, R. E., \& Ross, L. (1980). Human inference: Strategies and shortcomings of social judgment. Englewood Cliffs, NJ: Prentice-Hall.

Pham, M. T. (2004). The logic of feeling. Journal of Consumer Psychology, 14, 360-369.

Schneider, D. J., Hastorf, A. H., \& Ellsworth, P. C. (1979). Person perception. Reading, MA: Addison-Wesley.

Schwarz, N. (2004a). Metacognitive experiences in consumer judgment and decision making. Journal of Consumer Psychology, 14, 332-348.
Schwarz, N. (2004b). Meta-cognitive experiences: Response to commentaries. Journal of Consumer Psychology, 14, 370-373.

Schwarz, N., \& Clore, G. L. (2007). Feelings and phenomenal experiences. In A. W. Kruglanski, \& E. T. Higgins (Eds.), Social psychology. Handbook of basic principles (2nd ed., pp. 385-407). New York: Guilford.

Strack, F., Werth, L., \& Deutsch, R. (2006). Reflective and impulsive determinants of consumer behavior. Journal of Consumer Psychology, 16, 205-216.

Trope, Y., Liberman, N., \& Wakslak, C. (2007). Construal levels and psychological distance: Effects on representation, prediction, evaluation, and behavior. Journal of Consumer Psychology, 17, 83-95.

Wyer, R. S., Hung, I. W., \& Jiang, Y., (in press). Visual and verbal processing strategies in comprehension and judgment. Journal of Consumer Psychology.

$\mathrm{Xu}$, J., \& Schwarz, N. (2005). Was it long ago or unimportant? Diverging inferences from difficulty of recall. Paper presented at the annual meeting of the Society for Consumer Psychology St. Petersberg, FL. 